\title{
Notas sobre la formación humana en las urbes
}

\author{
Ana Ma. Valle Vázquez* \\ El gran sacrificio es, cuando hay elección preferir \\ al pequeño; y es porque del gran sacrificio nos \\ resarcimos admirándonos a nosotros mismos, lo \\ que no es posible con el pequeño.
}

Nietzsche (Humano demasiado humano)

Resumen: El escrito tiene como principal propósito reflexionar en torno a las relaciones que pudiese haber entre sacrificio y ciudad. Para ello nos centramos en lo más elemental de lo que uno y otra pueden significar. La principal pregunta que guía esta reflexión es ¿qué elementos del sacrificio pueden encontrarse en lo que llamamos ciudad? No se pretende hacer un análisis exhaustivo de estas nociones tan profundas y complejas, sino que partiremos de los significados más primarios, desde Durkheim, Mauss y Simmel, para centrar nuestra atención en sus vínculos. Al final nos preguntamos ¿es posible el espíritu del Don en el espacio urbano donde impera la economía monetaria? Asumimos que la profanación del vínculo y del espíritu del Don de nada es inevitable en las urbes, sin embargo, en el dar, recibir y devolver habita la nada como el espíritu del Don, y esta es la sangre que no se está dispuesto a pagar aunque simulemos que se otorga en las cosas que intercambiamos. Plabras clave: sacrificio, ciudad, formación, identidad, vínculo.

\section{Presentación}

E I escrito tiene como principal propósito reflexionar en torno a las relaciones que pudiese haber entre sacrificio y ciudad. Para ello nos centramos en lo más elemental de lo que uno y otra pueden significar. No se pretende hacer un análisis exhaustivo de estas nociones tan profundas y complejas, sino que partiremos de los significados más primarios para centrar nuestra atención en sus vínculos.

Desde el punto de vista metodológico se parte de la noción de Totalidad en las ciencias sociales revisado por Henri Lefebvre, desde esta perspectiva metodológica se acepta que la reflexión en torno a la relación sacrificio y ciudad no se limita a la pura y simple descripción de ambos hechos de manera aislada (2011: 106). Mirar la relación entre sacrificio y ciudad como Totalidad conlleva aceptar que esta relación "no es colocada fuera de lo humano, en una brutal objetividad, no es concebida como una pura trascendente subjetividad" (Lefebvre, 2011: 108). El acercamiento a la Totalidad, como metodología de análisis de la relación sacrificio y ciudad, conlleva principalmente algunos elementos:

\author{
* Profesora de la \\ Facultad de Filosofia \\ y Letras - Unam. \\ <anvallev@gmail. \\ com>. Ana Valle \\ (Ed.), Alteridad \\ entre creación \\ y formación. \\ Reflexiones en torno \\ a la cultura y la \\ educación. México: \\ Unam, 2012.
}


- El método dialéctico: donde el "mundo" se desdobla para el conocimiento en abstracto y concreto, pensamiento y realidad, el concepto y lo dado, donde estos dos mundos sólo hacen uno. Lo abstracto y lo concreto de la relación sacrificio y ciudad constituyen una Totalidad, pero los dos, dice Lefebvre, constituyen el Universo "porque cada uno de ellos contiene esencialmente un momento que corresponde al otro" (2011: 112). Lo concreto del sacrificio y la ciudad es la vida real de los seres humanos, en su infinita complejidad, así como lo abstracto son las concepciones que puedan tenerse de ciudad y sacrificio. Es en lo concreto, en lo más común y banal de la vida cotidiana que aparece la riqueza y complejidad de la Totalidad.

- La relación de causalidad: aquí lo real se ofrece como una mezcla de las relaciones de causas y de efectos. Cada causa reenvía a otra causa, todo efecto deviene causa a su vez. El sacrificio es causa de la ciudad al tiempo que la ciudad es causa del sacrificio. El sacrificio es efecto de la ciudad y la ciudad es efecto del sacrificio. "La causa aparece como efecto y el efecto como causa" (Lefebvre, 2011: 113). La ciudad se constituye a partir de los sacrificio, los sacrificios sólo son posibles en la comunidad citadina.

Bajo esta noción de Totalidad se acepta, siguiendo a Lefebvre:

En un sentido, que todo acto social, toda cultura todo pensamiento hasta el más abstracto, toda imagen hasta la más fantástica, permanece ligada a la naturaleza; más aún: permanece un hecho de la naturaleza. Imposible separar naturaleza de cultura. Pero, en otro sentido, todo objeto, toda realidad alcanzada, es un hecho humano, una conquista del hombre, un 'producto' de su actividad, por la cual se realiza. Lo uno no impide lo otro, al contrario (Lefebvre, 2011: 121).

El sacrificio y la ciudad manifiestan el hombre de la naturaleza y el hombre de la cultura. En el sacrificio urbano, entendido, como veremos más adelante, como hacer algo sagrado en lo difuso y vertiginoso de la economía monetaria, une lo cultural con lo natural.

El texto pretende hacer un análisis de la relación sacrifico y ciudad, a partir de Durkheim y sus concepciones en torno a lo religioso y la solidaridad, Mauss desde su noción del Don de nada, y Simmel desde la economía monetaria y la actitud blasée. De esta manera en principio se presentan algunos elementos generales sobre la expansión, la confusión y el vértigo tan propios de la vida citadina; posteriormente si aceptamos que el sacrificio es "hacer algo sagrado" ¿dónde está lo sagrado y el sa- 
crificio en la ciudad?; además si el sacrificio es un acto sagrado de solidaridad, como se apunta, ¿qué forma de solidaridad conlleva el sacrificio urbano? Si aceptamos que el acto sacrificial congrega, reúne o hace comunidad, y que estas congregaciones son relativas a creencias y prácticas en torno a lo sagrado, y esto es lo que se llama iglesia en su sentido social más profundo ¿cómo podemos pensar estos lugares y actos de reunión en la vida citadina? Finalmente nos preguntamos ¿es posible el espíritu del Don en el espacio urbano donde impera la economía monetaria? ¿cómo se establecen los vínculos en lo expansivo, lo confuso y lo vertiginoso de las ciudades? Asumimos que la profanación del vínculo y del espíritu del Don de nada es inevitable en las urbes, sin embargo en el dar, recibir y devolver habita la nada como el espíritu del Don, y ésta es la sangre que no se está dispuesto a pagar, aunque simulemos que se otorga en las cosas que intercambiamos.

\section{Ciudad o expansión inestable de súbditos}

Empecemos por lo que puede significar elementalmente ciudad: civitas atis "conjunto de ciudadanos" ; a su vez civis, ciudadano, puede significar también súbdito o subordinado. Y probablemente podamos decir que esta subordinación sea a algo llamado institución (en forma de Estado o Empresa), a diferencia de una subordinación a la Naturaleza y sus leyes. Y ésta puede ser una característica elemental de lo que llamamos ciudad. El espacio urbano no sigue el tiempo del espacio rural, las urbes viven al margen de los ciclos naturales y más bien producen sus propios ritmos; digamos que los tiempos urbanos no son naturales. Aunque el suelo, la luz, incluso el tiempo urbano no sean los del campo, uno y otro, ciudad y campo, entrecruzan sus modos y ritmos de vida. Evidentemente las murallas, físicas o fiscales, que limitaban y dividían al campo de la ciudad han caído desde hace más de dos siglos. Como señala Simmel,

\footnotetext{
la vida en la pequeña ciudad de la Antigüedad y de la Edad Media interpuso barreras para prevenir el movimiento y las relaciones del individuo hacia el exterior, como también levantó vallas para contener la independencia y la diferenciación individual. La naturaleza de estas barreras era tal que el hombre actual la consideraría insoportable (Simmel, 2005: 6).
}

Antaño, lo rural era lo externo, el espacio rural deviene ahora limitado y escaso ante la explosión del espacio urbano, y si bien es cierto que las murallas divisorias de ladrillos han caído, las ciudades de ahora han levantado otros muros de contención basados en la economía monetaria, como veremos más adelante, donde lo interno y externo se puede dar entre riqueza y pobreza. En fin, lo que interesa decir aquí es que el tiempo y el espacio de las urbes son expansivos y difusos, provocados por el crecimiento desmesurado de la población, lo que ha tenido como consecuencia que la ciudad sea la que rodee a los campos y no al revés, por tanto resulta muy compleja la 
definición de ciudad en tanto es complicada la fijación de sus límites. Habitar la ciudad es aceptar que se está subordinado a la expansión, no de la vida, sino de los espacios, del tiempo y de las personas que se extienden con pretensiones de ocupar o estar en demasía, se ocupa el espacio, el tiempo y a los otros con cálculos gigantescos, todo es mucho, más, demasiado. También en la ciudad se asume vivir difusa y vertiginosamente, la inestabilidad en este sentido es una de las cualidades más comunes en los ciudadanos. No hay claridad ni seguridad de casi nada, cada vez los ciudadanos tienen menos garantías que les procuren cierta calma. La vida citadina queda sometida a la vorágine de la expansión y de la confusión. Aunado a esto difícilmente podemos negar que la vida en la ciudad es vertiginosa, que conlleva esta sensación de movimiento que turba los sentidos, que marea, trastorna y desequilibra, que provoca inseguridad y miedo por el intenso dinamismo tan propio de las ciudades. Este trance, posesión, convulsión, frenesí y éxtasis que es el vértigo, según lo llama Roger Callois (1994: 144148), aunado al carácter expansivo y difuso de la ciudad, asegura la cohesión de la vida colectiva en las urbes.

En este sentido podemos decir que la ciudad es el conjunto de súbditos de la expansión fagocitante, de lo amorfo y del vértigo. ¿¿De qué manera está o no el sacrificio en esta vida expansiva, difusa y vertiginosa tan propia de la ciudad? Para atender esta cuestión veamos primero qué podemos entender por sacrificio.

\section{Fabricación de lo sagrado}

Sacrificar, desde su raíz etimológica (sacer: sagrado y facere: hacer) quiere decir "hacer algo sagrado" al tiempo que puede significar "convertir algo en sagrado". Si aceptamos que lo sagrado refiere a objetos (como sujetos, acciones, cosas, etcétera) que están separados y prohibidos de lo profano, entonces podemos decir que "hacer algo sagrado" implica el establecimiento de relaciones al margen de lo mundano. Lo sagrado es aquello interdicto por su carácter santo o sacrílego. En principio podemos decir que los atributos de lo sagrado forman parte de las actividades religiosas, entendidas éstas como la propia vida en comunidad, como el acto de congregar, reunir o atar. Siguiendo a Durkheim:

Una religión es un sistema solidario de creencias y prácticas relativas a cosas sagradas es decir separadas, prohibidas, creencias y prácticas que unen en una misma comunidad moral, llamada iglesia [eccleša: asamblea o reunión], a todos los que se adhieren a ellas (Durkheim, 2008: 92-93).

Así podemos decir que el sacrificio como "hacer algo sagrado" es esta relación recíproca entre los miembros de una comunidad, unión o congregación realizada en torno a lo prohibido. El sacrificio es un acto sagrado de solidaridad. Y justo por ello el 
sacrificio es del orden de lo religioso, en tanto congrega o reúne a la comunidad en torno a asuntos separados o prohibidos para ella, aunque paradójicamente deriven de la comunidad misma. No podemos dejar de atender que no hay comunidad humana posible, no es posible la ciudad en la que no existan prohibiciones (Durkheim, 2008: 462), tales prohibiciones limitan e indican modos de actuar, maneras de estar, ritmos de vida, ciclos y períodos en una comunidad, podríamos decir que gracias a lo sagrado, como lo prohibido, es posible con-vivir y con-morir en la ciudad.

Lo que une o ata en la vida religiosa es lo sagrado, por ello en esta vida lo profano debe quedar fuera. "La vida religiosa y la vida profana no pueden coexistir en un mismo espacio" (Durkheim, 2008: 474). La abstención, la renuncia, como separación de lo profano, es lo que posibilita la vida religiosa. Lo sagrado y el sacrificio logran hacer comunidad, por tanto podríamos decir que logran religión y ciudad. Sin embargo ¿dónde está lo sagrado y el sacrificio en la ciudad? ¿Dónde está lo separado y prohibido de lo profano en la vida citadina? ¿Dónde está el hacer y la conversión de algo en sagrado, en la ciudad? Sin mayores pretensiones que reflexionar sobre estas cuestiones, podemos decir que sin duda hay una diferencia radical entre las fuerzas divinas representadas por Zeus, Odín, Tezcatlipoca, incluso Jesucristo, y las fuerzas económicas de Carlos Slim (Telmex), Bill Gates (Microsoft), Amancio Ortega (Inditex) y Bernard Arnault (LVMH). Ambas fuerzas marcan y condicionan los modos de vida ideales, hacen sacrificios al convertir o fabricar cosas o estilos de vida en algo sagrado. Aquellos que tienen las fuerzas económicas, hacen, en tanto fabrican, las cosas prohibidas que mueven al mundo, producen las cosas sagradas. Ciertamente como afirma Simmel:

La metrópoli siempre ha sido la sede de la economía monetaria. Es aquí donde la multiplicidad y concentración del intercambio económico le otorga a los medios de intercambio una importancia que el volumen del comercio rural no le hubiese permitido. [La economía monetaria guarda una actitud casual respecto al trato con los hombres]. El dinero hace referencia a lo que es común a todo; el valor de cambio reduce toda calidad a la pregunta ¿cuánto cuesta? (Simmel, 2005: 2).

Las fuerzas económico-monetarias de los hombres más ricos del mundo, no sólo producen artefactos o cosas consumibles sino que fabrican modos de vida, fijan lo sagrado en las cosas que ellos hacen, como veremos más adelante. En las ciudades es posible preguntar ¿cuánto cuesta lo sagrado? ¿cuánto cuesta el sacrificio? sencillamente porque las fuerzas monetarias establecen lo prohibido, lo inalcanzable como ideal de vida. La economía monetaria fija el trato que habrá entre los hombres, dado que las relaciones sociales son dadas entre productores, socios, distribuidores y clientes; así el suelo citadino es el más fértil para establecer casualidades o coincidencias con lo sagrado desde los tratos comerciales. De igual manera en "las sedes de la economía 
monetaria", como Simmel llama a las ciudades, vemos que aquellas prohibiciones que posibilitan la vida colectiva, están marcadas por los modos de actuar, ritmos y ciclos de producción e intercambio mercantil establecidos por quienes tienen la fuerza económica para hacerlo; desde luego que estos estilos de vida son análogos al carácter expansivo y dinamismo vertiginoso de los grande monopolios trasnacionales. En otras palabras, los hombres más ricos del mundo con sus empresas establecen el precio, el tiempo y el espacio del sacrificio y por tanto de lo sagrado; para los citadinos es claro cuánto, cuándo y dónde acceder a las cosas sagradas. La fertilidad de las ciudades se establece por las coincidencias con la sagrada economía monetaria. Lo que se mantiene y se renueva en el sacrificio urbano es la relación entre los ciudadanos con las fuerzas de la economía monetaria. Este sacrificio urbano que es hacer algo sagrado como conjunto de súbditos, desde la expansión fagocitante y amorfa de la urbe. En la ciudad, una de las principales funciones de la fuerza económica monetaria es asegurar a los hombres lo sagrado y su necesidad de consumo. Lo que sucede entonces es un mercado entre el hombre y la economía del dinero, el trato que se establece con lo sagrado es comercial. Así podemos decir que lo sagrado es mercancía, al mismo tiempo que ésta es sagrada en tanto se fabrica como cosas y estilos de vida prohibidos e ideales. El sacrificio urbano, como hacer algo sagrado en lo difuso y vertiginoso de la economía monetaria, es tanto para quienes fabrican las cosas sagradas como para los ciudadanos que les rinden culto. Es interesante esta coincidencia con lo que Durkheim en su momento llamó "corrupción de la idea primitiva de sacrificio" a propósito de las interpretaciones de Smith. Así dice Durkheim:

\footnotetext{
La idea de sacrificio-ofrenda, sólo pudo nacer [según Smith] en el seno de las grandes religiones, [o de las grandes ciudades] en las que los dioses desligados de las cosas con las que se identificaban primitivamente, fueron concebidos como reyes, propietarios eminentes de la tierra y sus productos. A partir de ese momento el sacrificio se asimiló al tributo que los súbditos [o ciudadanos] pagan a sus príncipes como pago de los derechos que les otorgan. Pero esta nueva interpretación habría sido en realidad una alteración, e incluso una corrupción, de la idea primitiva. Pues "la idea de propiedad materializa todo lo que toca" y al introducirse en el sacrificio lo desnaturalizó convirtiéndolo en una especie de mercado entre el hombre y la divinidad (Durkheim, 2008: 520).
}

Efectivamente la idea de "propiedad" materializa todo lo que toca, como señala Durkheim, así como la idea de "economía monetaria" mercantiliza todo lo que toca. ¿No será acaso que la alteración o lo corrupto no es tanto la interpretación de Smith sino la mutación propia del sacrificio urbano? Hacer algo sagrado, sacrificar, en la ciudad es alterar o corromper el sacrificio mismo, dado que lo sagrado se fabrica, se vende y se compra. 


\section{Rareza de la solidaridad}

Como hemos dicho coincidimos con Durkheim respecto a que el sacrificio es un acto sagrado de solidaridad, sin embargo, si bien es cierto el sociólogo francés no deja claro, en su definición de religión, a qué tipo de solidaridad se refiere, si mecánica u orgánica, vale la pena distinguirlas y decir algo respecto a su relación con el sacrificio y la ciudad. La solidaridad mecánica está dada por el principio de semejanza donde la personalidad individual se desvanece en el grupo, ya no somos nosotros mismos, sino el ser colectivo, dice Durkheim, "la solidaridad que deriva de las semejanzas alcanza su maximum cuando la conciencia colectiva recubre exactamente nuestra conciencia total y coincide en todos sus puntos con ella" (1993: 140). Mientras que la solidaridad orgánica es aquella que está en la división del trabajo, donde los unos difieren de los otros y cada uno de los individuos tiene una esfera de acción que le es propia, aquí lo colectivo deja descubierta una parte de lo individual, así dice Durkheim, "la sociedad hácese más capaz para moverse con unidad, a la vez que cada uno de sus elementos tienen más movimientos propios" (1993: 142). En la solidaridad mecánica el individuo es como un objeto poseído que sigue aquello que le imprime su propietario, mientras que en la solidaridad orgánica el individuo es como cada órgano de un cuerpo, con su particular fisonomía y función, sabiendo que la unidad del organismo es mayor que la de sus partes. En la ciudad ¿el sacrificio se establece como solidaridad mecánica o bien como solidaridad orgánica? Sin mayores pretensiones que un mero intento por esbozar una posible respuesta a esta cuestión, podemos decir que el sacrificio en la ciudad responde raramente a ambos tipos de solidaridad. A la solidaridad orgánica matizada por la conveniencia y la indiferencia, es decir, si bien es cierto que nos subordinamos al colectivo de la empresa, la escuela, las redes sociales como Facebook o Twitter; la solidaridad se establece momentáneamente por aquello que nos conviene individualmente siendo indiferentes a lo que ocurre con lo colectivo, somos egoístas e indiferentes al no sentir ni inclinación ni repugnancia hacia algo llamado comunidad, incluso hacia cualquier cosa, porque la vida colectiva en la ciudad parece ser cualquier cosa. Nos explicamos: la división del trabajo ahora está dada por las capacidades y funciones utilitarias individuales mientras respondan a la conveniencia del colectivo al que se pertenece más que a la adhesión solidaria a él. Somos solidarios y son solidarios con nosotros por conveniencia utilitaria y no por funciones especiales de división de trabajo. Los colectivos responden a intercambios mercantiles donde los individuos somos utensilios que se "usan y se tiran", sólo nos unimos al colectivo mientras éste nos ofrezca cierta protección ganada al demostrarle que le somos útiles, sin embargo cada vez son más comunes, en la dinámica de las ciudades, las prácticas de deshecho y desuso. Por su parte el sacrificio se establece como solidaridad mecánica cuando nos fundimos, literalmente, en la dinámica del colectivo citadino empresarial y escolar, por mencionar sólo dos, nos alineamos y nos uniformamos para con-fundirnos en la plebe pequeño burguesa de la elite empresarial o en la masificación corriente de 
la escuela. Los horarios y los espacios de las ciudades responden a estos ritmos del colectivo empresarial y escolar, son estos colectivos quienes deciden a qué hora y en dónde despertar, a qué hora y en dónde comer, a qué hora y en dónde "descansar", a qué hora y en dónde dormir, a qué hora y en dónde sentarse o sedentarizarse, a qué hora y en dónde transportarse, etc. Nos desvanecemos en los tiempos y lugares del colectivo urbano. Desde esta perspectiva enrarecida de la solidaridad mecánica y orgánica tan propia de lo urbano, lo que preocupa es la vulgarización del sacrificio. Es decir, si el sacrificio es "hacer algo sagrado" en tanto acto separado e interdicto de lo mundano, aquí, en la solidaridad urbana de conveniencia, indiferencia y utilitaria, el sacrificio, y con ellos lo sagrado, no sólo es tocado sino incluso devorado por la dinámica de la masa mundana. Confundirnos en la masa o distinguirnos de ella es "vivir" en lo mundano, es aceptar la agonía de lo sagrado. En la subordinación del ciudadano propia de la dinámica citadina hay una crucial tensión no de lo sagrado con lo profano, antes bien de lo colectivo con lo egoísta indiferente. Efectivamente, como afirma Simmel, "los problemas más profundos de la vida moderna [citadina] se derivan de la demanda que antepone el individuo, con el fin de preservar la [...] individualidad de su existencia frente a las avasalladoras fuerzas sociales" (2005: 1). Demandas que tensan lo individual con lo colectivo. Quizás ahora más que en otros tiempos, habitar en la ciudad se vuelve una mortificante tensión entre ser completamente iguales al tiempo que se busca ser completamente diferentes, incluso ser muy visibles con extravagancias metropolitanas al tiempo que se busca pasar inadvertido para salvaguardar un poco de "libertad" respecto a la vorágine de la ciudad. La rareza de la solidaridad urbana provoca que en ambos extremos (diferencia e igualdad) la vida colectiva, la vida religiosa, lo sagrado y por tanto el sacrificio sean imposibles. No se sacrifica lo individual en aras de lo colectivo, pero tampoco se sacrifica lo colectivo en pro de lo individual, sencillamente porque lo sagrado se ha profanado. Simmel diría que "el individuo se ha convertido en un simple engranaje de una enorme organización de poderes y cosas que le arrebata de las manos toda espiritualidad" (2005: 9). En la ciudad las fronteras de lo sagrado con lo profano se diluyen y se confunde con los márgenes de lo egoísta-diferenciado y lo colectivo-igualitario, ambos se mundanizan.

\section{Centro comercial, lugar de sacrificio}

Ahora bien, además de la solidaridad Durkheim señala, como hemos dicho, que las creencias y las prácticas que unen en una misma comunidad moral, se llama iglesia, aquél lugar y acto donde se llevan reuniones o asambleas en torno a lo sagrado. ¿Cómo podemos pensar esta noción de iglesia en la vida citadina? Probablemente el carácter difuso, expansivo y vertiginoso de la ciudad haga que este tipo de comunidades tengan igualmente modos de vida religiosa y eclesiástica indefinidos y fagocitantes. Difícilmente podemos negar que lo que ata a la comunidad de la urbe es un lazo extraño a lo sagrado, es casi imposible negar que resulta un tanto ridículo decir 
que las asambleas urbanas tengan un carácter eclesiástico ya que tanto los lugares como los momentos de reunión citadinas son raros a lo sagrado. Religión e iglesia urbanas pueden resultar demasiado mundanas con límites tan difusos, a no ser por aquellos lugares y momentos tan propios de las ciudades como los enormes centros comerciales o malls, como incluso los no anglos los hemos llamado, que unen a la comunidad en función de muchas cosas evidentemente prohibidas para la masa; o bien aquellas zonas fuertemente privilegiadas por su riqueza material y habitada por los grandes magnates que son explícitamente interdictas a la masa, probablemente estos lugares sean más cercanos a lo sagrado en tanto permanecen al margen de lo mundano. Pero las plazas comerciales, por dar sólo un ejemplo, son espacios donde las cosas prohibidas pueden ser vistas, tocadas e incluso comidas por los mundanos de la masa. Los llamados centros comerciales se convierten en los lugares y momentos de sacrificio, donde la vida religiosa y eclesiástica ocurre, al tiempo que en ellas, en las plazas comerciales, es posible profanar lo sagrado. En efecto, como afirma Durkheim, "Ios hombres no podrían vivir sin sus dioses, pero, por otro lado, los dioses morirían si no se les rindiera culto" (2008: 528). Los citadinos no podríamos vivir sin nuestras plazas comerciales y estos centros religiosos y eclesiásticos morirían si no les rindiéramos culto. La comunión dada en la vida colectiva establecida en los centros comerciales protege lo sagrado y profano porque ambos son resultado de la vida en comunidad. Ahora bien ¿toda vida religiosa-eclesiástica conlleva lo sagrado y, por tanto, el sacrificio en la ciudad? En estricto sentido sí, porque las fuerzas religiosas y morales, propias de los modos de vida presentados en los centros comerciales, por ejemplo, son tanto reales como ideales dado que son creaciones sociales. Sin embargo no necesariamente podemos afirmar que a mayor fuerza religiosa mayor fuerza sagrada y sacrificial. No podemos afirmar que a mayores ataduras, religare, reales o virtuales con la comunidad mayor sacrificio o mayores actos sagrados. Incluso, como siguiendo a Simmel (2005), a mayor gente, mayor cercanía corporal, mayor distancia espiritual, menor movilidad.

Lo que actualmente sucede son crímenes y no sacrificios como actos sagrados de solidaridad. Los actuales derramamientos de sangre han eliminado el sentido del sacrificio. Probablemente hemos vaciado a lo religioso y la iglesia de su núcleo sagrado, donde las relaciones humanas se han quedado sin espíritu y sin energía sagrada. La sangre, la muerte, el dolor, el sufrimiento, el "sacrificio" se han profanado. Lo que ahora ocurre parece ser el contagio de lo profano a lo sagrado (Durkheim, 2008: 492). Lo mundano toca, mira, nombra, incluso fagocita, a lo sagrado. Aquella explosión de la mancha urbana, tan propia de las ciudades, no sólo es la ventaja del asfalto sobre la vegetación, ni tampoco de la rapidez sobre la quietud, ni del ruido sobre el silencio, ni del gris sobre el verde, antes bien dicha explosión es de la masa sobre los vínculos de lo mundano sobre lo sagrado. 


\section{Profanación del espíritu del Don de nada}

Como apuntamos al principio, el sacrificio al hacer algo sagrado conlleva la vida colectiva propiamente dicha. No es posible hablar del sacrificio sin las ligaduras que hacen comunidad. El sacrificio, además de ser una acto de extraña solidaridad en la ciudad, puede ser un acto de don, un acto en el que se ofrece, en el que se otorga (Durkheim, 2008: 524). El sacrificio es un don en tanto convierte algo profano en sagrado. Si bien es cierto sacrificar significa "hacer algo sagrado" no es lo mismo "hacer algo" que "convertir algo en sagrado". La conversión implica una mutación o un cambio que afecta la forma. La metamorfosis radica no sólo en el movimiento sino en el cambio de forma, incluso podríamos decir que implica aquello que se ha llamado "devenir forma". ¿Qué es ese "algo" que se convierte en sagrado? El sacrificio es metamorfosis no sólo del tributo sacrificial, sino también de la comunidad quien y para quien se ofrece el sacrificio. Tributo que puede ser una vida humana encarnada en su propio cuerpo. Un cuerpo profano que tiene la posibilidad de mutar su condición en algo sagrado. Ese "algo" que se convierte en sagrado es lo profano mismo. Lo que se da es la conversión de la vida. El sacrificio permite cambiar lo que haya que cambiar de lo profano para dar lugar a lo sagrado. Lo que interesa resaltar aquí es que el sacrificio es la mutación de lo profano en lo sagrado como un acto de solidaridad y de don. En este darse, hacerse o convertirse está la separación, privación y prohibición de lo sagrado, y ello no es otra cosa que el desdoblamiento de lo profano en lo sagrado procurado por el acto sacrificial. En el sacrificio se materializa la tensión entre lo sagrado y lo profano, se encarnan los límites de la prohibición habida en lo sagrado. Si bien es cierto, como afirma Durkheim, que lo profano no debe tocar a lo sagrado (2008: 466), éste sólo es posible por la conversión de lo profano. No obstante es importante decir que la vida profana no es caldo de cultivo de la vida religiosa ni del sacrificio. ¿Qué es lo que hace que algo de lo profano se convierta en algo sagrado? Podemos decir que las ataduras que hacen comunidad. Si aceptamos, como hace Durkheim, que el sacrificio pertenece al culto positivo, es decir al de los deberes, al de los actos obligatorios, entonces podemos decir que el sacrificio es el máximo don, como acto de renuncia que vincula, es un gran acto donativo de comunión, de esta manera podemos decir que lo que hace que algo se convierta en sagrado es el sacrificio mismo, en este acto sagrado de solidaridad se habitan las ligaduras, los hilos que atan y tejen a una comunidad.

Ahora bien, el don como conversión vital puede potenciarse si atendemos el "Don de nada". De acuerdo con Marcel Mauss en su "Ensayo sobre los dones" se interroga: “¿Qué fuerza tiene la cosa que se da, que obliga al donatario a devolverla?" (1979: 157), en otras palabras ¿cuál es el espíritu del Don? De acuerdo con él, lo que ata, lo que vincula, lo que re-liga y hace comunidad es "nada", que no es vacío, antes bien es todo aquello que no es útil, que no es comprable porque no es vendible porque no es 
fabricable, que no es mercancía, que no es un artefacto. Lo que se intercambia bajo el principio de "el Don de nada"

no son exclusivamente bienes o riquezas, muebles e inmuebles, cosas útiles económicamente; son sobre todo gentilezas [...] en las que la circulación de riquezas es sólo uno de los términos de un contrato mucho más general y permanente (Mauss, 1979: 160).

Y nosotros nos preguntamos ¿ंes posible el espíritu del Don en el espacio urbano donde impera la economía monetaria? ¿cómo se establecen los vínculos en lo expansivo, lo confuso y lo vertiginoso de las ciudades? Ciertamente, como el mismo Mauss afirma:

el carácter voluntario, por así decirlo, aparentemente libre y gratuito [del Don de nada] y, sin embargo, obligatorio e interesado de esas prestaciones; prestaciones que han revestido casi siempre la forma de presente, de regalo ofrecido generosamente incluso cuando, en ese gesto que acompaña la transacción, no hay más que ficción, formalismo y mentira social, y cuando en el fondo lo que hay es la obligación y el interés económico [...] el mercado es un fenómeno humano que se produce en todas las sociedades (Mauss, 1979: 157-158).

¿Cuál es la fuerza, en las ciudades, que obliga a ejecutar los contratos de intercambio que crean vínculos? ¿En los conglomerados citadinos, en lo difuso, expansivo y vertiginoso de las urbes, en los centros comerciales, en las sedes de la economía monetaria, es posible el espíritu del Don que vincula? Ciertamente hay una diferencia entre la relación que pueda darse en la expansión de los ciudadanos de la economía del dinero, con aquello que vinculan bajo la premisa del Don de nada. En la ciudad podemos caminar entre ríos de gente, viajar en el amontonamiento del transporte público, habitar en un departamento donde literalmente estamos unos sobre de otros, y aun así no tener ningún vínculo con nadie. Por más conectados que estemos virtualmente, por más atados a la vida de los centros comerciales, etcétera, no necesariamente ocurre el vínculo basado en el Don de nada. En la ciudad lo que se profana es el vínculo al suponer que el espíritu del intercambio y de la mercancía está en su precio y no en su inutilidad. El sacrificio, ese "hacer algo sagrado o convertir algo en sagrado", lo que entraña es el Don de nada, porque en el acto sacrificial ocurre el dar, recibir y devolver lo más inútil: la sangre, el cuerpo, el tiempo, los gestos, las actitudes, las gentilezas: "no valen nada".

Ante esto, probablemente el Don de nada, en la ciudad, se encuentra en la resignación ya sea como "actitud blasée" (Simmel 2005: 4) o como "volverse a signar". Como actitud blasée la resignación está puesta en la incapacidad para reaccionar a 
la vorágine de la ciudad, es literalmente estar hastiado, son los ciudadanos hipnotizados, anestesiados porque han entregado toda su fuerza al dinamismo del vértigo urbano, de la fagocitante economía del dinero. Por su parte la resignación como volverse a signar es una torcedura que nos coloca en otro lugar, es volverse a dar un signo desde la necesidad mínima y suficiente, es doblar y desdoblar los signos de la ciudad para encontrar y otorgarse otro signo desde un sustine et abstine, aguanta y prescinde, sé capaz de aceptar la muerte y soportar la vida. Mientras que "la esencia de la actitud blasée radica en la inestabilidad ante la diferencia de las cosas [...] donde el significado y el valor diferencial de los casos se ignoran al no considerárseles substanciales" (Simmel, 2005: 4), el espíritu de volverse a signar está en la posibilidad de aguantar lo atroz de las equivalencias monetarias y en la imperturbabilidad ante la diferencia. De esta manera el Don de nada se establece en los intercambios habidos en la resignación ya sea como hastío o como vuelta a darse un signo. No es una resignación al sacrificio sino que en él se protege el espíritu del Don como resignación. En este sentido, aceptamos que, de una o de otra manera, en el Don de nada se debe pagar con un trozo de carne, como en "El mercader de Venecia", con la trampa de no ceder ni una gota de sangre. Digámoslo claramente: en la conversión de lo profano en sagrado, el sacrificio en la ciudad, podemos resignarnos a la economía monetaria y aceptar que aún en el intercambio mercantil de la propia vida, en donde se paga con trozos de carne, lo que permanece es la inutilidad, la nada, habida en la propia mercancía. En el dar, recibir y devolver habita la nada como el espíritu del Don, y esta es la sangre que no se está dispuesto a pagar, aunque simulemos que se otorga en las cosas que intercambiamos.

Abstract: The main purpose is to reflect on the relationships that could exist between sacrifice and city. To do this, we focus on the fundamental issue of what one and another may mean. The main question guiding this discussion is what elements of sacrifice can be found in that we call city? Not intended to provide a comprehensive analysis of these notions as deep and complex, but we will leave the primary meanings, from Durkheim, Mauss and Simmel, to focus our attention on the links. In the end we question is it possible the spirit of Gift in urban space ruled by money economy? We assume that the profanation of the link and the spirit of the Gift of nothing is inevitable in the cities, however, in giving, receiving and returning nothing, living the spirit of Gift, and this blood is not willing to pay, but let's pretend that the things given in exchange.

Keywords: sacrifice, city, education, identity, binding.

\section{Referencias}

Callios, Roger. Los juegos y los hombres. La máscara y el vértigo. México: Fondo de Cultura Económica, 1997.

DURKHEIM, Émile. Las formas elementales de la vida religiosa. Madrid: Alianza, 2008. La división del trabajo social. México: Colofón, 1993. 
LefEbVRE, Henri. La noción de totalidad en las ciencias sociales. Telos, v. 13, n. 1. Venezuela, Maracaibo, Universidad Rafael Belloso Chacín, Ene.-Abr. 2011, p. 105-124.

MAUSS, Marcel. Sociología y antropología. Madrid: Tecnos, 1979.

SIMMEL, Georg. La metrópolis y la vida mental. Santiago: Redalyc, Bifurcaciones 004, 2005. 